\title{
Leitura e consumo de livros, no Brasil, em tempos de Covid-19
}

\author{
Reading and consumption of books, in Brazil, in the days of Covid-19
}

Lectura y consumo de libros, en Brasil, en tiempos de Covid-19

Marília de Araujo BARCELLOS ${ }^{1}$

\section{Resumo}

O presente estudo reúne um levantamento com leitores e consumidores de livros durante a epidemia de Covid-19, considerando-se a coleta de dados a partir de respondentes universitários do Departamento de Ciências da Comunicação da Universidade Federal de Santa Maria. O levantamento, em conjunto com análise proveniente de pesquisas do setor, traça um panorama com resultados disruptivos em virtude de hábitos adquiridos de março do ano de 2020 a setembro do ano seguinte.

Palavras-chave: Leitura; Consumo; Mercado editorial; Indústria do livro; Covid-19.

\begin{abstract}
This study brings together research with book readers and consumers during the Covid-19 epidemic, based on data collection with university students from the Department of Communication Sciences at the Federal University of Santa Maria. The survey, together with analysis from industry research, outlines a panorama with disruptive results due to habits acquired from March 2020 to September of the following year.
\end{abstract}

Keywords: Reading; Consumption; Publishing Market; Book industry; Covid-19.

\section{Resumen}

Este estudio reúne investigaciones con lectores y consumidores de libros durante la epidemia de Covid-19, basado en la recolección de datos con estudiantes universitarios del Departamento de Ciencias de la Comunicación de la Universidad Federal de Santa María. Con el análisis de la investigación de la industria, perfila un panorama de resultados disruptivos por hábitos adquiridos desde marzo de 2020 hasta septiembre del año siguiente.

${ }^{1}$ Dra. em Letras pela Pontifícia Universidade Católica do Rio de Janeiro (PUC-Rio) - Professora Associada do Departamento de Ciências da Comunicação da Universidade Federal de Santa Maria (UFSM) - E-mail: mariliabarcellos@gmail.com. ORCID: https://orcid.org/o00o-0001-7143-8649. 
Palabras clave: Lectura; Consumo; Mercado editorial; Industria del libro; Covid-19.

\section{Introdução}

O ano de 2020 ficará na história como aquele que acarretou muitas perdas em todos os níveis humanos, por conta do surto epidêmico de Covid-19, o que acabou por evidenciar nas pessoas em geral a capacidade de enfrentar desafios outros, como a criação de novos hábitos. O presente artigo, motivado pela relevância do livro enquanto produto comunicacional, suporte pleno de valor simbólico que carrega parte do processo civilizatório de uma nação, visa apresentar a investigação realizada com jovens universitários sobre mudanças nos hábitos de leitura e de consumo de livros no Brasil em seus diferentes suportes de apreensão dos conteúdos (impresso, $e$ book, audiobook), apontando tendências que venham a se instaurar no período póspandemia.

A questão norteadora prevê uma reflexão a respeito de como o isolamento em tempos de pandemia influenciou no comportamento em relação à leitura, a partir do universo acadêmico em uma universidade pública e federal, no período de ensino em Regime de Exercícios Domiciliares Especiais (REDE) ${ }^{2}$. Nota-se que, durante tal período, os alunos pesquisados estavam alocados em várias cidades do país.

A investigação elege estudantes de graduação e da pós-graduação do Departamento de Ciências da Comunicação da Universidade Federal de Santa Maria (UFSM) como objeto de estudo e emprega, enquanto pilares na discussão, os dados das pesquisas realizadas pelo setor, em grande maioria procedentes de entidades de classe ou elaboradas em instância governamental.

\section{Povo educado, povo feliz}

O Brasil não é um país de leitores. Sem demora percebe-se isso ao acompanharmos os dados divulgados em pesquisas, sobre os quais nos debruçaremos mais adiante. Mas, dentro desse cenário, o grupo aqui definido situa-se numa fatia privilegiada da população, com acesso ao nível superior, e que tem apresentado, ao

\footnotetext{
${ }^{2}$ O Regime de Exercícios Domiciliares Remotos foi adotado na UFSM por instrução normativa no dia 17 de março de 2020. Disponível em: https://www.ufsm.br/proreitorias/prograd/2020/o3/17/prograd-publica-instrucao-normativa-n-o02-2020-regula-o-regimede-exercicios-domiciliares-especiais-rede-e-o-funcionamento-da-proreitoria-de-graduacao-prograd-edepartamento-de-registro-e-contro/. Acesso em 20 dez. 2021.
} 
longo dos anos, a maior proporção de leitores, conforme registra a socióloga Zoara Failla, responsável, desde 2006, pelos projetos do Instituto Pró-livro (IPL), que organiza as mais bem sedimentadas pesquisas sobre o setor no país, dentre as quais a Retratos da Leitura no Brasil3 (2019). Ela lembra que cerca de 50\% dos brasileiros não são leitores de livros, e desses, menos da metade lê um livro inteiro a cada três meses, referindo-se ao critério de uma das pesquisas do IPL, sendo que a "maior proporção de leitores" se encontra entre quem tem nível superior de escolaridade (FAILLA, 2021, p. 95).

O Programa Internacional de Avaliação de Alunos (PISA, 2019), organizado pela Better Policies for Better Lives (OCDE), fornece a avaliação mundial mais abrangente e rigorosa dos resultados de aprendizagem dos alunos. A edição de 2018 revelou que o Brasil está classificado como um dos países com baixo índice de educação e leitura, ocupando a $57^{\mathrm{a}}$ posição no ranking dos 77 participantes na categoria Proficiência em leitura. A conjuntura é alarmante, conforme destaca a economista Mariana Bueno, da Nielsen Books. Ao referenciar o relatório produzido pelo Banco Mundial, World Development Report (2017), ela destaca: “(...) se tudo o mais se mantiver constante levaremos 260 anos para que os estudantes brasileiros consigam atingir o mesmo nível de proficiência em leitura que a média detectada pela OCDE” (BUENO, 2021, p. 79).

Ela complementa a argumentação mencionando que, para além do direito fundamental do acesso à leitura e ao conhecimento, os indicativos educacionais também dizem respeito ao desenvolvimento socioeconômico. Diante disso, compreende-se o quanto há de ser realizado em prol de mais leitores e consumidores conscientes face à oferta cada vez mais híbrida.

\section{Pilares norteadores de informações}

Debater o cenário editorial pós-pandêmico desde perspectivas que considerem a leitura e o consumo de livros por parte de estudantes universitários requer um resgate das pesquisas do setor para situar esse universo de leitores frente ao comportamento do mercado em geral. O mercado editorial brasileiro reúne, há

\footnotetext{
3 A pesquisa em âmbito nacional, a Retratos da leitura no Brasil, é realizada pelo Instituto Pró-Livro e está em sua $5^{\text {a }}$ Edição. Tem como objetivo indicar o comportamento do leitor e registrar os indicadores de leitura dos brasileiros.
} 
décadas, uma série de pesquisas que contribuem como fonte de dados para estudos na Comunicação e áreas afins.

Dentre a literatura disponível pode-se relacionar algumas referências organizadas por entidades de classe e amplamente divulgadas na internet. Estudos encomendados pela Câmara Brasileira do Livro (CBL), pelo Sindicato Nacional dos Editores de Livros (SNEL), pela Associação Nacional de Livrarias (ANL) e pelo Instituto Pró-livro (IPL) são encontrados nas referências ao estado da arte e usualmente referenciados como pilares em investigações científicas que consideram a produção e vendas no mercado editorial, reflexões a respeito dos índices de leitura e, sobretudo, o consumo de livros no varejo, por exemplo.

O cenário do mercado editorial antes da pandemia destaca a situação a que a indústria do livro vinha sendo submetida com a crise de grandes redes de livrarias, entre elas a Saraiva e a Cultura. O livreiro e presidente da ABL, Bernardo Gurbanov, afirma que a crise é percebida desde 2014 “(...) juntamente ao início do maior período recessivo da história econômica do país, até a chegada da pandemia da Covid-19 (...) quando entra em campo um novo fator: mais uma vez as novas tecnologias e sua influência na modelagem dos hábitos de consumo" (GURBANOV, 2021, p. 57).

Assim sendo, o consumo e a oferta em tempos pandêmicos sofreram alterações ao longo do tempo, inicialmente com a retração no movimento dos editores de lançarem obras novas e em adquirir expertise para lidar com canais de venda alternativos aos presenciais, preferindo reforçar os já existentes para a comercialização. Por sua vez, os hábitos de leitura nem sempre acompanharam os de consumo. Tal dualidade é explicada a partir de relatos de estudantes acerca da leitura de livros disponíveis em seus acervos pessoais, em casa: os tais livros ainda não lidos e que tiveram sua "poeira sacudida" diante do isolamento social proporcionado pelo confinamento, como será visto adiante.

Uma das pesquisas sobre as vendas de livros junto aos consumidores, intitulada Painel do varejo de livros no Brasil (2021), promovida pelo Sindicato Nacional dos Editores de Livros (SNEL) e Nielsen Book4, aponta para um recuo na produção editorial no início da pandemia, conforme os dados levantados. Os três primeiros meses da pandemia (março, abril e maio de 2020) são significativos de um

\footnotetext{
4 A Nielsen Book, sob encomenda do SNEL, disponibiliza mensalmente o relatório sobre o comportamento do varejo no mercado do livro no Brasil. Com fins de facilitar a leitura neste artigo, a partir deste momento, esta pesquisa será denominada Painel do varejo.
} 
período dedicado a estratégias de sobrevivência, seja na seara da saúde ou na econômica. De maneira que, para fins de compreensão do cenário macro, que implica na percepção do micro, abordamos a comparação entre as vendas no início da pandemia, quando, conforme veremos a seguir, os estudantes declararam terem mantido um alto índice de leitura.

Em abril de 2020, o varejo de livros no Brasil perdeu 47,6\% do seu faturamento em relação ao mesmo mês do ano anterior, pré-pandemia. "As lojas fechadas impactaram negativamente, mas, em maio, a queda foi menor" (NETO, 2020), anuncia a reportagem que articulou as informações sobre a pesquisa Painel do varejo. Já em novembro de 2021, o faturamento surge com saldo positivo, quando a mesma pesquisa divulga um aumento considerável nas vendas. É relevante destacar que a Painel do varejo realiza o levantamento junto ao caixa das livrarias e, portanto, reflete uma amostragem considerável das aquisições de livros.

Para fins do presente estudo, em que são avaliados os dados de estudantes em seus hábitos durante um período de ensino em REDE, pressupõe-se que tal amostragem leve em consideração o contexto no qual o consumo ocorreu, comparado aos índices autodeclarados de aquisição realizados pelos respondentes. Também cabe lembrar que livros adquiridos não pressupõem livros lidos, e vice-versa. De maneira que os hábitos de leitura podem divergir do período de maior volume de compras e de faturamento apresentado por pesquisas como a Produção e vendas do setor editorial5 (2020), que coleta os dados diretamente das editoras.

Outro aspecto interessante a ser considerado é o subsegmento do livro técnico, científico e profissional (CTP). Essa categorização obedece à classificação utilizada pelo setor na pesquisa Produção e vendas, que divide o mercado em vendas governamentais do mercado em si, ao mesmo tempo em que distingue as publicações em quatro categorias de livros, a saber: didáticos, obras gerais, religiosos e CTP.

A categoria dos livros didáticos apresentou uma variação de $12 \%$ a menos no faturamento no ano acumulado até abril de 2021, por conta do fechamento das escolas e do acesso ao conteúdo à distância, de um ano para o outro, conforme acompanhamos nos resultados da pesquisa Mercado de livros do Brasil/ Números no setor (2021), realizada pela GfK (Growth from Knowledge) e pela Associação Brasileira de Livrarias. A pesquisa ainda aponta que, neste mesmo período,

5 Produção e Vendas do Setor Editorial a partir deste momento, a fim de facilitar a leitura, será denominada como Produção e vendas. 
HQ/Jogos, literatura estrangeira, ciências e temáticas sobre concurso público foram os gêneros com destaque positivo. Ao passo que livros de direito, didáticos e dicionários apresentaram desempenho negativo. No contexto pandêmico, as vendas acabaram beneficiando os e-books e os audiolivros, embora não tenhamos respondentes, entre os universitários na micropesquisa, que tenham se apresentado como usuários de audiolivro.

Ainda de acordo com a pesquisa Painel do varejo $^{6}$, as vendas diminuíram nos meses de março a maio de 2020, com aumento nos meses de junho e julho, seguido de queda e ressurgimento das vendas/consumo em dezembro, à época das festas. A variedade na aquisição de títulos pelo consumidor, considerando-se o período de 22 de abril de 2020 a 19 de maio de 2020, em relação ao mesmo período do ano anterior, apresentou uma perda de $17,17 \%$ no surgimento de ISBNs7, portanto, uma baixa na bibliodiversidade nesse período de pandemia em relação ao pré-pandêmico. Segundo a pesquisa Produção e vendas "em 2020, as editoras brasileiras produziram 46 mil títulos - desse total, 24\% são lançamentos (novos ISBNs) enquanto $76 \%$ são reimpressões. Dessa forma, o número de lançamentos em 2020 (11.295) caiu 17,4\% no comparativo com 2019" (CBL; SNEL; NIELSEN BOOKS, 2021), referindo-se ao ano-base de 2020. No ano seguinte, ao se comparar o mesmo período de março a maio de 2021 em relação a 2020, houve um aumento de 94,20\% e um reaquecimento não só na produção de ISBNs como um crescimento de $43,78 \%$ na diversidade do consumo (SNEL; NIELSEN BOOK, 2021).

Há de se ponderar que a relação entre venda de livros pelas livrarias não revela o número de livros lidos, mas sim o faturamento das editoras. No entanto, o aumento do índice de leitura permite o engajamento em novas aquisições, e consulta a acervos disponíveis, como clubes de assinaturas e bibliotecas.

Diante disso, o presente texto tem a pretensão de reunir uma pequena amostragem dos hábitos de leitura e de consumo de leitores universitários no período da pandemia. O levantamento há de servir como fio condutor do comportamento de leitores localizados fora das capitais (em sua maioria), e o acesso ao livro, por meio da

${ }^{6}$ Painel do Varejo. Disponível em: https://snel.org.br/wp/wpcontent/uploads/2021/o6/SNEL_05_2021_-_05T_2021.pdf. Acesso em 10 de nov. 2021. 7 Expedido no Brasil pela Câmara Brasileira do Livro, o ISBN (International Standard Book Number/ Padrão Internacional de Numeração de Livro), é conhecido informalmente como a "carteira de identidade do livro", por configurar-se como registro obrigatório a cada novo título ou reedição, por isso é usado aqui como parâmetro do aumento ou não da produção editorial, ao mesmo tempo que a variante de consumo de diversidade de títulos. 
aquisição via digital, aguçado pelo confinamento, além de todos os outros aspectos que esse cenário acarretou. A seguir, passamos a abordar o campo no qual os leitores e consumidores estão inseridos.

\section{Configuração do campo e suas peculiaridades}

$\mathrm{O}$ que revelam os hábitos praticados por leitores e consumidores de livros durante o isolamento social, provocado pela Covid-19? Os leitores podem acessar os conteúdos à sua escolha - no Kindle, no Ipad, no notebook, no celular - e mexer na formatação desse conteúdo, alterando o pano de fundo, a tipografia, a cor, o tamanho da fonte. Ao mesmo tempo que se observam mudanças relacionadas à comercialização dos produtos, no caso do livro, a disruptura na leitura induz a maneiras diferenciadas de práticas e de circulação dos textos. A economia da mídia é acompanhada da economia dos textos, que, por sua vez, foi importante para permitir o maior acesso à leitura, por meio da maior circulação dos textos, com baixa no preço médio dos livros (BARBIER, 2018, p. 234).

O filósofo Edgar Morin (2020) aponta para o momento atual, em que entramos numa era de incertezas. Segundo ele, "nunca estivemos tão fechados fisicamente no isolamento, e nunca tão abertos para o destino terrestre. Estamos condenados a refletir sobre nossos caminhos, nossa relação com o mundo e sobre o próprio mundo" (MORIN, 2020, p. 19). Medidas restritivas, como proibição de aglomerações e limitação da liberdade de ir e vir, foram determinantes para que se pudessem estabelecer hábitos diferenciados. A propagação do digital viu-se acelerada pela condição de sobrevivência em todos os âmbitos, tanto na vida pessoal como na doméstica e profissional.

Mais recentemente, o sociólogo John B. Thompson (THOMPSON, 2013), no lastro de postulados desenvolvidos por Pierre Bourdieu sobre noções do campo e bens simbólicos, estabelece a existência da pluralidade de campos por sobre o ciclo sistêmico da cadeia produtiva do livro e o lugar dos agentes e as relações entre eles. Percebe-se, pois, um roteiro que se inicia na indústria criativa, passando pelo agente, indo para a editora (que processa o produto em todas suas fases, até chegar à gráfica), quando começa a circular. Segue então para as vendas, o marketing, a distribuição, os locais de difusão - mais especificamente, as livrarias (virtuais e físicas), vendas 
governamentais e leitores, ouvintes, telespectadores. Isso se se considerar o modelo tradicional, sem a ruptura da autopublicação.

John B. Thompson (2013) desdobra conceitos sobre o campo editorial para explicar que esse mercado é composto, na verdade, por uma pluralidade de campos. Explica-se: cada um deles - campo de livros didáticos, campo de livros comerciais, campo de livros de arte, entre outros - funciona mais ou menos da mesma maneira, embora possuam regras, conceitos, estratégias, objetivos e percepções que os diferem uns dos outros. Uma obra de boa qualidade no campo da literatura infantil, por exemplo, não é a mesma coisa que uma obra de boa qualidade no campo de publicação de livros profissionais. Da mesma forma, deve-se entender que os planos de marketing dos dois ramos de publicações provavelmente não serão também tão parecidos. Desse modo, especificidades são chamadas pelo autor de "lógicas de campo".

O sociólogo reforça a noção de campo, sob a perspectiva de lógica, com normas que passam para uma pluralidade de campos. A teoria dos campos serve para ajudar a enxergar como "agentes, firmas e outras organizações nunca existem isoladamente: encontram-se sempre em complexas relações de poder, competição e cooperação com outras firmas e outras organizações”, ou seja, funcionam todas elas dentro de um sistema (THOMPSON, 2013, p.10). A cadeia de valor do setor editorial envolve, pelo menos, quinze elementos que interagem entre si, em camadas sobrepostas e concomitantes, em ciclos sistêmicos de início, na criação, e fim, no consumo.

As relações sociais no campo permitem incluir a diversidade dos agentes, a diversidade das situações e das instâncias de poder. Cada agente encontra-se em uma esfera. O pequeno livreiro, aquele do estabelecimento de rua, não está na mesma esfera de uma rede de livrarias, e tampouco no quesito dos marketplaces $^{8}$. Tratam-se de cruzamentos distintos. É cabível imaginar o tanto de diferenças que são encontradas, e, somando-se a isso, vem a reflexão do tanto de peculiaridades que há dentre as múltiplas esferas.

Se, por um lado, têm-se empreendimentos distintos, em relação a porte, catálogo, estratégicas; por outro, enfrentam-se sujeitos distintos entre si, tanto para quem produz, faz circular, e detém o poder de fazer difundir determinada ideia, pelo

\footnotetext{
8 Conforme o livro A Jornada como transformação digital, marketplace "é um modelo de negócios que surgiu no Brasil em 2012, também conhecido como uma espécie de shopping center virtual. É considerado vantajoso para o consumidor, pois reúne diversas marcas e lojas em um só lugar" (LOBÃO; ZILLI, 2020, p. 495).
} 
seu conteúdo e materialidade, quanto para quem recebe os conteúdos invólucros, sejam eles da materialidade que forem, disponíveis em quaisquer dispositivos.

No Brasil, marketplaces como a Amazon, com seus sistemas de recomendações pelos usuários, por exemplo, têm se destacado utilizando o comércio social como estratégia de conectar consumidores entre si e, assim, alavancar essas conexões com propósitos comerciais. Cenário que distancia, cada vez mais, a gigante transnacional de pequenos e médios livreiros, mesmo que muitos deles ocupem um lugar no varejo. $\mathrm{O}$ fato de estar fora do contato direto com o consumidor enfraquece um dos pontos fortes do profissional do livro: o atendimento personalizado, presencial e a diversidade dos produtos na loja física. É esse, pois, o cenário desvelado e acelerado pela pandemia.

\section{Os universitários: um microcosmo de leitores e consumidores}

O levantamento realizado neste artigo manifesta menos a missão de ser uma pesquisa aprofundada, e mais um roteiro de tópicos abordados para a compreensão de um recorte da geração que hoje se encontra entre 17 e 30 anos, mais especificamente, a denominada Geração $\mathrm{Z}^{9}$, caracterizada por pessoas nascidas entre os anos 1995 e 2010 (o período varia conforme a literatura utilizada) ${ }^{10}$. Refere-se a pessoas que passaram a infância e adolescência convivendo com os dispositivos eletrônicos e com a disseminação de plataformas como o Google e a Amazon à sua disposição.

O nível educacional do recorte da sondagem abarca estudantes universitários de graduação e pós-graduação. Além disso, os participantes caracterizam-se pelo fato de estarem vinculados ao ensino público, em nível federal, e por estarem amplamente distribuídos no território nacional já que, de março de 2020 a setembro de 2021,

\footnotetext{
9 Para mais detalhes a respeito da geração Z, indicamos a leitura do livro Zconomy: como a geração Z vai mudar o futuro dos negócios - e o que fazer diante disso, de Jason Dorsey e Denise Villa (2021). ${ }^{10} \mathrm{O}$ recorte geracional é utilizado por demógrafos e cientistas sociais como parâmetros para definir princípios científicos da pesquisa social. Longe de enquadrar sujeitos em estereótipos temporais, o presente trabalho pretende, por meio das gerações, apontar comportamentos destacados dentre os participantes que possam estar relacionados com vivências históricas, no caso da Geração Z:

universitários reconhecidos como nativos digitais. Cabe destacar que, como conceito, a categoria está sob constante observação. Em julho de 2021, o jornal norte-americano The Washington Post publicou uma reportagem com a posição de demógrafos e cientistas sociais contra a promoção da categorização geracional pela agência de pesquisa Pew Research Center, uma vez que o uso de rótulos de geração (a Geração Silenciosa, baby boomers, Geração X, millennials e agora Geração Z) não corresponderia à realidade social. No entanto, ratificamos que para fins de definição de época com eventos históricos, econômicos, sociais atinentes ao período dos participantes deste trabalho considera-se pertinente tal classificação.
} 
permaneceram com aulas em REDE (Regime de Exercícios Domiciliares Especiais), ou seja, no regime de ensino remoto, mediado por tecnologias educacionais durante a suspensão das atividades presenciais.

O roteiro elaborado, conforme assinalado anteriormente, situa a pesquisa de consumo em um público leitor, com recorte de estudantes universitários, a fim de tornar possível a abordagem a partir de tópicos importantes para o mercado, com amostragem de interesses, hábitos e comportamento de compra adquiridos durante a pandemia.

O levantamento foi elaborado a partir do Departamento de Ciências da Comunicação da Universidade Federal de Santa Maria ${ }^{11}$ (também intitulada Facos, por carregar, historicamente, a denominação da Faculdade de Comunicação). A cidade está localizada no interior do Estado do Rio Grande do Sul, espaço fronteiriço situado ao sul do Brasil. Trata-se de uma perspectiva microcósmica, com um cenário fora do eixo de capitais, revelando a descentralização e até mesmo uma certa diversidade territorial - cerca de 30\% dos estudantes respondentes são provenientes de cidades de fora de Santa Maria.

As questões servem de fio condutor para a compreensão do tecido de relações em meio aos agentes da rede que compõem o entrelaçamento entre os participantes do complexo campo da edição e que repercutem em aprendizagens e práticas distintas daquelas em que costumavam atuar no período pré-pandemia. E, em especial, no que diz respeito a modelo de negócios, à condução das práticas de venda e de consumo.

A pesquisa teve início com a definição dos participantes, a saber: alunos dos quatro cursos da Facos, tanto da graduação (Relações Públicas-RP; Produção Editorial-PE; Jornalismo-JO e Publicidade e Propaganda-PP) quanto do Programa de Pós-graduação em Comunicação (POSCOM). A representatividade dos respondentes foi menor no curso de Jornalismo-JO, com 6,2\%; seguida de Publicidade e Propaganda-PP, com 7,7\%; de Produção Editorial-PE, com 49,2\%, e de Relações Públicas-RP, com 18,5\%, empatando com a participação dos alunos da POSCOM.

\footnotetext{
${ }^{11}$ A micropesquisa, parte do projeto de pesquisa em andamento intitulado Leitura e consumo de livros na Facos, foi realizada entre os dias 8 e 12 de outubro de 2021, por meio das redes da Facos, que compreende Facebook dos alunos, grupos de WhatsApp e grupo de e-mail. Os alunos no

Departamento de Ciências da Comunicação, segundo dados apurados em novembro de 2021, totalizam 604 inscritos, sendo 507 na graduação e 97 matrículas ativas na pós-graduação. Essas informações foram atualizadas para esta publicação. Os percentuais referidos no texto são de junho de 2021, em que o número de alunos era um pouco maior.
} 
Segundo os dados levantados, a amostra soma cerca de 13\% do total de alunos inscritos no departamento. A micropesquisa foi realizada entre os dias 8 a 12 de outubro de 2021, por meio das redes da Facos, que compreendem o Facebook dos alunos, grupos de WhatsApp e grupo de e-mail.

Os universitários respondentes, em sua maioria, têm idades entre 17 e 25 anos, configurando o perfil que atende como Geração Z, como já mencionado, isto é, aqueles nascidos a partir de 1995 e até 2010. Conhecer as características do comportamento do consumidor por faixa etária é importante, dentro do contexto econômico, social e político-cultural em que se desenvolveu a amostragem. Nesse caso, os estudantes nascidos a partir de 1995 configuram-se como nativos digitais, por terem tido potencialmente contato, desde a infância, com equipamentos e dispositivos digitais. Não se pode afirmar que todos possuíram em mãos, desde sempre, computadores, smartphones e outros dispositivos, mas, diante do desenvolvimento de ferramentas informatizadas em alta velocidade, em especial nos primeiros anos do século XXI, estão inseridos em uma época de mudanças de hábitos do analógico para o digital, seja na implementação de fibra ótica e da mudança da TV para o digital, seja no surgimento dos primeiros leitores de livros digitais, como o Kindle e o Ipad, até às condições favoráveis para a autopublicação.

A Geração Z caracteriza-se também pela realidade do trabalho em casa, pela maior inclinação ao empreendedorismo e pela busca de um mundo melhor, mais sustentável ${ }^{12}$. Considerando-se, pois, que a geração adulta hoje apresenta o perfil de consumidor cada vez mais digital, é compreensível que a pandemia tenha facilitado esse hábito. Segundo Ronsini (2007), as mídias são potentes ferramentas comunicacionais, mediadas pelas tecnologias de comunicação. Ela se refere à experiência totalizante da circulação da mídia - revista, jornal, televisão, rádio, cinema, livro, CD, videocassete/DVD, computador - no espaço doméstico ou no espaço público" (RONSINI, 2007). O que nos leva a crer que, a partir do que nos aponta Ronsini, o acesso à leitura é favorecido em gerações que dominam as ferramentas para o consumo. Durante a pandemia de Covid-19, em que o espaço privado se viu invadido pelo público/profissional, quem tinha domínio dos códigos de

\footnotetext{
${ }^{12}$ Segundo a pesquisa Millenium Survey, realizada pela consultoria Deloitte, $42 \%$ da chamada geração $\mathrm{Z}$ dizem ter aprofundado sua relação com empresas e produtos que adotam práticas sustentáveis. Disponível em Poder360: <(https://www.poder360.com.br/pesquisas/42-da-geracao-z-preferemempresas-com-praticas-sustentaveis-diz-pesquisa/2>. Acesso em 10 jan. 2022.
} 
uso do ambiente virtual conseguiu acessar as informações com mais rapidez e amplitude. No caso dos respondentes da pesquisa, é um diferencial.

Em relação à localização dos respondentes da amostra coletada junto aos discentes, 30,3\% eram de fora do Estado do Rio Grande do Sul, espalhados pelo território nacional, com a seguinte distribuição: São Paulo (12,1\%); Distrito Federal (4,5\%); Rio de Janeiro (4,5\%); Pará (3\%); Paraná (3\%), Minas Gerais (1,52\%); Piauí (1,52\%). Os respondentes do Rio Grande do Sul equivaliam a 69,7\% da amostra. O universo levantado revela informações de alunos de todas as regiões do Brasil: Sul (72,7\%); Sudeste (18,12\%), Centro-Oeste (4,5\%); Norte (3\%) e Nordeste $(1,52 \%)$.

A UFSM, por se tratar de uma instituição pública, de âmbito nacional, congrega estudantes de todo o país; além disso, foi a primeira universidade federal criada fora de uma capital brasileira, possuindo três campi, conforme dados do relatório UFSM em números ${ }^{13}$, disponibilizados pela Pró-Reitoria de planejamento, em 2021. Além disso, na edição de 2021, a instituição obteve destaque do Academic Ranking of World Universities, ao ocupar o $29^{\text {a }}$ lugar como melhor Universidade da América Latina e Caribe, de acordo com o Latin America University (UFSM, 2021).

Uma vez apresentado o perfil do recorte dos respondentes, passa-se, agora, às respostas que norteiam a análise, a fim de abordar as mudanças nos hábitos de leitura em tempos de Covid-19. Na pandemia, as certezas caíram por terra, transformando o contexto em algo caótico. Em se tratando de um cenário que retrata o período da pandemia, foi considerada a situação dos respondentes em relação à Covid-19, observando que tal contexto pode afetar os hábitos dos leitores. Nesse sentido, o microcosmos evidencia que, no período em que a doença avançava, com maior número de óbitos, de abril a setembro de 2021, registrou-se diminuição do fluxo de leitura. Entre os respondentes, 46\% declararam-se nessa situação, o que possibilita indicar que a perda de familiares e a conjuntura de incertezas podem ter sido fatores para a diminuição do índice de livros lidos. Leu-se mais no primeiro semestre do ano de 2020 do que no segundo semestre.

A curva começou a decair em 2021, sendo que o maior percentual de queda ocorreu em junho-julho e, justamente um ano depois do início da pandemia, constatou-se o menor índice de leitura, cujo aumento só foi retomado a partir de setembro de 2021. O perfil do consumo de obras pelos discentes, no gênero ficção,

${ }^{13}$ Disponível em: https://portal.ufsm.br/ufsm-em-numeros/publico/index.html. Acesso em 29 dez. 2021. 
revela uma tendência por livros no estilo jovem adulto, além da literatura de fantasia e de obras gamificadas. As categorias eleitas pelos universitários correspondem aos resultados de crescimento no faturamento em HQ/jogos, ficção e literatura estrangeira registrados no ano acumulado até junho de 2021 do relatório Mercado de livros/Números do setor (2021). Embora tenha sido identificado na pesquisa que a categoria artes/comunicação - relacionada tematicamente aos cursos da Facos -, tenha se mantinho em um patamar positivo, não chegou a corresponder ao interesse demonstrado pela ficção diante do isolamento social. No âmbito das respostas, a preferência por obras de ficção foi evidenciada e pouco surge a presença do livro CTP nas leituras. Uma hipótese a ser considerada é o download de PDFs piratas na internet nesse subsegmento, como denomina a pesquisa Produção e vendas.

Nessa amostragem, o comportamento do consumidor de livros indica dispersão para outras plataformas. Para aqueles que mantiveram o hábito da leitura, percebe-se uma migração gradual para o $e$-book $(36,9 \%)$, embora se registre ainda uma maioria que opta pela aquisição de impressos. Mas o que os leitores declararam ter feito quando estavam lendo menos? A verdade é que os interesses encontraram-se distribuídos, entre outras modalidades de entretenimento, pelas redes sociais.

Considerando-se ainda o fluxo de leitura após o consumo dos livros, a partir da seguinte pergunta: “comprou e leu em seguida ou os deixou para outra ocasião?”, percebe-se que um percentual de $66,2 \%$ dos respondentes na micropesquisa assumiram ter deixado para lê-los posteriormente, isto é, somente 33,8\% dos estudantes leram as obras assim que efetuaram a compra. O dado revela uma reduzida associação entre compra e leitura. Embora tenha havido um aumento do acervo pessoal de livros (independentemente de seu formato) entre os respondentes, não houve, necessariamente, o crescimento no nível de leitura nesse período. Ao mesmo tempo, os números apontam para um cardápio maior de opções de leitura em casa no futuro. Aqui abre-se um leque de possibilidades para futuras investigações que tratem da apropriação do objeto livro e da significação do livro possuído, mas que por ora não é o foco desta pesquisa.

Um número muito alto dos respondentes declarou ter aproveitado para ler livros do acervo da casa, independentemente de terem sido adquiridos durante a pandemia: $95,4 \%$. Outros 63,1\% responderam ter utilizado o acesso gratuito na internet para a leitura; $52,3 \%$ indicaram usar bibliotecas digitais e uma minoria, 
21,5\%, disseram ter pedido livros emprestados (as respostas não eram excludentes). Solicitou-se, ainda, a indicação de novos dispositivos e aplicativos utilizados durante a epidemia do coronavírus, e, entre os relacionados, surgiram o Kindle, o Skoob, o Skeelo, o Wattpad, o Prateleira e o Google Play. Contudo, a maioria afirmou não ter adquirido esse hábito.

O pesquisador e editor Whaner Endo, ao analisar as pesquisas sobre o consumo de livro digital, relatou ter havido aumento de títulos disponíveis na internet, tanto pagos quanto gratuitos, crescimento esse justificado como estratégia de investimento por parte das editoras, em período pandêmico (ENDO, 2021). De acordo com o levantamento realizado com os estudantes da Facos, ocorreu um aumento do consumo dos e-books. Isso se deu em função da quantidade de livros gratuitos ofertados, em abril de 2020, quando o mercado avaliava qual era a melhor tomada de decisão para as vendas, sob uma condição nunca antes enfrentada. $O$ dado não surpreende, apenas aponta para a facilidade encontrada no manuseio das plataformas, e o constante aprimoramento do e-commerce.

Para atender aos consumidores ávidos pelas facilidades disponíveis, é imprescindível considerar a existência e a permanência de uma rede de entrega rápida e eficiente, atendida em parte, no Brasil, pela capilarização dos Correios. Se as plataformas de venda atenderam às necessidades do consumidor restrito ao isolamento social durante a pandemia, é de se pensar no papel da leitura como formadora de massa crítica e a manutenção das vendas e dos empréstimos após a retomada de circulação de pessoas. Isso implica acesso presencial às livrarias, com eventos culturais.

Conforme entendem os respondentes, uma das características das livrarias presenciais é o atendimento humanizado, mesmo que 58,5\% deles tenham admitido não terem sentido falta desse tipo de atendimento. Tal resultado é passível de compreensão pela questão geracional, que apresenta facilidade com a ambiência digital desde a infância. Outra informação que delimita a moldura do consumo é a preferência pela compra em lugares fora de onde se encontravam $(75,4 \%)$. Tendência nada surpreendente, aliás, uma vez que as opções de marketplace vêm crescendo, e que, durante a pandemia, fortaleceram-se. No entanto, o que chama atenção é o percentual de consumo que se efetuou também em locais próximos à moradia (41,5\%). Melhor dizendo, a compra em estabelecimentos menores se fez presente, mesmo com o fechamento eventual do comércio. Isso demonstra uma prática de 
consumo que permaneceu e que poderá ser retomada com mais vigor no decorrer da volta à normalidade.

A pesquisa Painel e varejo (2021) acompanha a evolução dos dados mensalmente, a cada compra realizada em livrarias cadastradas. Ela registrou um aumento do desconto médio de 2020 para 2021. Os dados da amostragem Leitura e consumo de livros na Facos revelam que quase a totalidade dos respondentes $(92,3 \%)$ consideram esse item na hora da compra; no entanto, há um percentual alto que abriria mão do desconto em prol da bibliodiversidade. Tal resultado pode ser explicado a partir do perfil dos respondentes, já que, inseridos no âmbito universitário, muitos consideram outros fatores para além do preço. Quiçá em outro segmento de formação a resposta teria sido diferente.

Em relação à cultura digital, o fato de o hábito do consumo por meio de $e$ commerce ter sido identificado na amostragem não constitui uma garantia de que, após a pandemia, os leitores manterão a aquisição via internet, seja do livro analógico, seja de conteúdos digitais. No entanto, segundo resultados da pesquisa Estudos novos, hábitos digitais em tempos de Convid-19 (2020), realizada pela Sociedade Brasileira de Varejo e Consumo (SBVC) em maio de 2020, registrou-se que, após experimentarem o comércio eletrônico em novas categorias, muitos pretendem continuar comprando mais on-line do que faziam antes da Covid-19.

Ao longo da história, as práticas de leitura estão relacionadas ao suporte ao qual a escrita se instaura. No caso de nossos hábitos durante a pandemia, poder-se-ia arriscar a dizer que novas lógicas no consumo e de leitura podem ter implicações sociológicas profundas. De maneira que o livro, assim como o vemos hoje, no formato códice, teve sua envergadura levada para as telas de smart TV, de celulares e de computadores com mais frequência do que poderíamos supor até muito recentemente. Como foi levantado, o uso de $e$-books e de hábitos para além do livro impresso foram ampliados com veemência. A cadeia produtiva teve seus desafios e agora precisa se reestruturar em busca de compreender e atender o consumidor que aqui se instaura.

\section{Considerações finais}

O cenário trazido pela pandemia de Covid-19 irrompeu acelerado e de modo inusitado em meio ao caos da tentativa de reorganização da vida cotidiana. 
Permaneceram movimentos já existentes, é bem verdade, mas com as limitações advindas e as mudanças infligidas ao cotidiano, impuseram-se novas restrições e tendências. $O$ fato é que alterações implicaram em mudanças não só no comportamento do consumidor, mas na lógica do campo e na relação entre os agentes da cadeia produtiva, em especial na venda e no consumo de livros.

A partir dos dados coletados com os universitários, nesta micropesquisa, percebe-se que, apesar da compra de livros digitais ter aumentado, eles mantiveram a aquisição de livros impressos. No entanto, o mercado registrou um aumento significativo nas vendas no formato digital. Não somente o consumo foi transformado: a oferta de títulos digitais aumentou entre editoras que mantinham apenas os impressos em seus catálogos.

Cabe salientar que muitos dos respondentes compraram livros digitais, mas também físicos e outra parcela passou a ler, inicialmente, os que já tinham em casa, incluindo livros de bibliotecas universitárias, com prazo estendido para a devolução devido à necessidade de implementação do ensino remoto. Tal dado pode explicar a baixa nas vendas identificada pelo setor no faturamento das editoras e das livrarias no início de 2020 e a crescente retomada em meados de 2021, quando os estudantes reiniciam o consumo de livros.

Percebe-se que, à medida que o tempo avança, o consumo de livros aumenta com destaque para o letramento digital, uma vez que a leitura em suportes digitais cresce. Isso caracteriza uma alteração no hábito de leitura e indica a aprendizagem adquirida. O mesmo ocorre com o acesso às obras por meio da internet a qualquer horário, forçosamente à distância pelas condições pandêmicas. Os depoimentos dos alunos indicam o retorno do consumo em livrarias presenciais após a pandemia, mas simultaneamente a manutenção do hábito de leitura digital.

Contudo, a relação entre o consumo e a leitura do livro digital deve ser percebida de maneira separada. Isso porque, nos períodos de maior retração do mercado, apontado pelas pesquisas, a saber início de 2020, houve um maior índice de leitura por parte dos respondentes, que afirmam ter lido mais de março a maio, com uma queda ao longo do ano, com exceção dos meses de junho e dezembro, cuja curva ascende, adentrando 2021. A alta de faturamento no primeiro período de 2021, conforme aponta a Mercado do Livro no Brasil/ Números do setor (2021), não corresponde ao consumo dos universitários, isto é, foram meses de maior leitura entre os universitários, mas de menor aquisição. 
A pandemia requereu ampliação de acervos e acessos, uma vez que aos agentes da cadeia produtiva foram solicitadas formas inovadoras de se comunicar e de se relacionar com o público. O acesso de conteúdo por meio das telas foi amplificado. As bibliotecas universitárias, com restrição ao atendimento presencial, migraram para os ambientes virtuais, a fim de atenderem à demanda dos alunos. As plataformas de leitura digital tiveram mais acessos do que imaginaram e as editoras migraram para a produção de $e$-books, apontando uma redução de lançamentos no formato impresso. A tendência é a manutenção dos clientes no modo e-commerce somado ao retorno aos eventos presenciais em livrarias e bibliotecas.

Livrarias, editoras e lojas virtuais fizeram do e-commerces seu suporte de vendas e de vitrine dos produtos e serviços durante a pandemia. Isso provocou uma aceleração de novas tendências já apontadas, mas, para alguns, nunca dantes imaginada na prática. Quais são, portanto, os fatores que romperam com práticas no processo de venda e consumo de livros, aqui considerados como conteúdos disponibilizados digitalmente ou não, e publicados seja por editoras, seja pelo próprio autor?

Longe de abrir a discussão para a substituição, ou não, do impresso pelo digital/sonoro, a questão aqui é menor que essa. Para reflexões futuras, cabe a pergunta: quais as condições financeiras, tecnológicas e regulatórias necessárias para que o processo de aprendizagem do comportamento de compra e vendas on-line, adquirido durante a pandemia, tenha uma continuidade construtiva? A entrega dos produtos, a divulgação, os eventos on-line e off-line, políticas públicas que permitam a bibliodiversidade e a descentralização do poder são contribuições necessárias.

O cenário do período pandêmico aponta para a necessidade de investimento em equipamentos, em conexão tecnológica e em recursos humanos que dominem os ambientes digitais. Ao mesmo tempo, mesmo que em ritmo lento, seria desejável a retomada dos eventos presenciais, com a participação dos leitores e autores, a circulação física pelos corredores das livrarias. É uma tendência o uso das informações disponíveis na internet para a comparação de preços na hora da compra, isto é, o fato de estar em uma livraria física não necessariamente indica o consumo no estabelecimento. Existe a possibilidade do acesso on-line e a compra do produto na loja virtual. Essa já é uma tendência declarada por alguns livreiros.

As ferramentas mudaram. Não há mais como fugir das experiências causadas pelo isolamento social e o acesso pleno ao mundo digital pelos 
leitores/consumidores. E quem a isso resistir corre o risco de desaparecer, uma vez que a leitura resiste em seu patamar de existência, mesmo que diante da diversidade de opções de entretenimento.

A pandemia permitiu aos usuários uma maior intimidade com o mundo digital e a ampliação do letramento nessa modalidade. Essa aprendizagem é uma tendência para o período pós-pandemia. Diante disso, conclui-se que compreender a lógica do jogo que se instaura entre os atores e entidades a partir da análise do campo editorial permite tecer novos cenários e recortar vestimentas adaptáveis a tempos atuais.

Por fim, considera-se que a questão norteadora inicial foi atendida. A experiência em tempos de pandemia influenciou no comportamento dos consumidores e dos leitores de livros no perfil de consumidores pesquisados. Alunos matriculados nos cursos da Facos/UFSM, em sua maioria, mantiveram o hábito da leitura, pelo menos durante alguns meses entre março de 2020 a setembro de 2021. No entanto, há de se levar em conta aqueles que se tornaram não-leitores no período, uma vez que declararam ter diminuído, ou mesmo abandonado o hábito de leitura, demonstrando uma mudança no comportamento. Porém, o dado não surpreendente, uma vez que a Retratos da leitura já apontava, em 2019, "um decréscimo de 91\% para 86\%” (FAILLA, 2021, p. 95) entre os respondentes com nível superior de escolaridade.

Além disso, é possível afirmar que os discentes aumentaram as habilidades de letramento digital na navegação por novos dispositivos, que já lhes eram familiares e que correspondem a características geracionais. Também inseriram a leitura de entretenimento como hábito junto a tantas outras possibilidades de lazer.

Cabe destacar que a referida investigação tem menos a pretensão de carregar um modelo único de tendência, e mais o intuito de apontar para a multiplicidade de aspectos que podem e devem ser explorados no âmbito da pesquisa acadêmica considerando vários eixos e recortes, permitindo a descentralização de informações e microsondagens que possam perceber os detalhes e especificidades e virem a compor um todo, ao longo do tempo. 


\section{Referências}

ASSOCIAÇÃO NACIONAL DAS LIVRARIAS (ANL); GFK. Mercado do livro no Brasil/

Números do setor. São Paulo, 2021. Disponível em:

<https://www.anl.org.br/v1/numeros-do-setor/ >. Acesso em 11 dez. 2021.

BARBIER, Frédéric. A Europa de Gutenberg: o livro e a invenção da modernidade ocidental (Séculos XIII-XVI). São Paulo: Edusp, 2018.

BARCELLOS, Marília de Araujo (coord). Leitura e consumo de livros na Facos, projeto de pesquisa, Santa Maria: Universidade Federal de Santa Maria, 2021.

BUENO, Mariana. O livro como elemento do desenvolvimento socioeconômico. In: LOUZADA, Daniel (org.). Livros para todos: ensaio sobre a construção de um país de leitores. Rio de Janeiro: Nova Fronteira, 2021.

CÂMARA BRASILEIRA DO LIVRO (CBL); SINDICATO NACIONAL DOS EDITORES DE LIVRO (SNEL); NIELSEN. Pesquisa produção e vendas no setor editorial brasileiro. São Paulo, 2020. Disponível em <https://snel.org.br/pesquisas/>. Acesso em 10 nov. 2021.

COHEN, Philip N. Opinion: Generation labels mean nothing. It's time to retire them. The Washington Post, Washington, DC, 7 jun. 2021. Disponível em $<$ https://www.washingtonpost.com/opinions/2021/o7/o7/generation-labels-mean-nothingretire-them/>. Acesso em 8 jan. 2022.

DORSEY, Jason; VILLA, Denise. Zconomy: como a geração Z vai mudar o futuro dos negócios - e o que fazer diante disso. Rio de Janeiro: Agir, 2021.

ENDO, Whaner. Olhar digital - Um mapa editorial para avaliar a presença do livro digital no Brasil. In: CONGRESSO BRASILEIRO DE CIÊNCIAS DA COMUNICAÇÃO, 44., GP PRODUÇÃO EDITORIAL, 2021, Virtual. Anais...Virtual: Intercom, 2021. Disponível em: <https://www.portalintercom.org.br/eventos1/congresso-nacional/20213 2 . Acesso em 10 nov. 2021.

FAILLA, Zoara. O brasileiro que lê, lê o quê? In: LOUZADA, Daniel (org). Livros para todos: ensaio sobre a construção de um país de leitores. Rio de Janeiro: Nova Fronteira, 2021.

GURBANOV, Bernardo. Mais respiradores e menos tributos para as livrarias do Brasil. In: LOUZADA, Daniel (org). Livros para todos: ensaio sobre a construção de um país de leitores. Rio de Janeiro: Nova Fronteira, 2021.

INSTITUTO PRÓ-LIVRO. Retratos da leitura no Brasil. São Paulo, 2019. Disponível em: $<$ https://www.prolivro.org.br/5a-edicao-de-retratos-da-leitura-no-brasil-2/a-pesquisa-5aedicao/ $\geq$. Acesso em 12 dez. 2021.

LOBÃO, Luis; ZILLI, Carlos. A Jornada da transformação digital. São Paulo: Lamonica, 2020.

MORIN, Edgar. É hora de mudarmos de vida. Rio de Janeiro: Bertrand, 2020.

NETO, Leonardo. Maio foi melhor do que abril. Ainda assim, varejo de livro registra queda de 33\%. PublishNews, São Paulo, 2 jun. 2020. Disponível em < 
https://www.publishnews.com.br/materias/2020/o6/o2/maio-foi-melhor-do-que-abril.ainda-assim-varejo-de-livro-registra-queda-de-33>. Acesso em 1 dez. 2021.

PISA 2018 revela baixo desempenho escolar em leitura, matemática e ciências no Brasil. Portal do MEC, Brasília, 3 de dez. de 2019. Disponível em< http://portal.mec.gov.br/busca-geral/211-noticias/218175739/83191-pisa-2018-revelabaixo-desempenho-escolar-em-leitura-matematica-e-ciencias-no-brasil>. Acesso em $29 \mathrm{dez}$. 2021.

42\% da geração $Z$ preferem empresas com práticas sustentáveis, diz pesquisa. Poder 360, Brasília, 5 set. 2021. Disponível em <https://www.poder36o.com.br/pesquisas/42-dageracao-z-preferem-empresas-com-praticas-sustentaveis-diz-pesquisa/ $>$. Acesso em 11 jan. 2021.

RONSINI, Veneza Mayora. Mercadores de sentido: consumo de mídia e identidades juvenis. Porto Alegre: Sulina 2007.

SINDICATO NACIONAL DOS EDITORES DE LIVRO (SNEL); NIELSEN BOOK. Pesquisa Painel do varejo de livros no Brasil. São Paulo, 2021. Disponível em < https://snel.org.br/pesquisas_>. Acesso em 1 nov. 2021.

SOCIEDADE BRASILEIRA DE VAREJO E CONSUMO - SBVC. Estudos novos hábitos digitais em tempos de Convid-19. São Paulo, 14 mai. de 2020. Disponível em< https://sbvc.com.br/novos-habitos-digitais-em-tempos-de-covid-19/>. Acesso em 14 mai. 2021.

THOMPSON, John B. Mercadores de Cultura: o mercado editorial no século XXI. São Paulo: Unesp, 2013.

UFSM sobe no ranking das melhores universidades da América Latina segundo a THE. UFSM, Santa Maria, 2 ago. 2021. Disponível em<https://www.ufsm.br/proreitorias/prograd/sisu/2021/o8/o1/ufsm-sobe-no-ranking-das-melhores-universidades-daamerica-latina-segundo-a-the/>. Acesso em 29 dez. 2021.

WORLD Development Report 2018: Learning to realize education's promise. World Bank, Washington, 4 out. 2017. Disponível em <https://elibrary.worldbank.org/doi/abs/10.1596/978-1-4648-1096-1>. Acesso em 29 dez. 2021.

Este é um ARTIGO publicado em acesso aberto (Open Access) sob a licença Creative Commons Attribution, que permite uso, distribuição e reprodução em qualquer meio, sem restrições, desde que o trabalho original seja corretamente citado. 